\title{
Resposta da ABRAPLIP à proposta do MEC de retirada da literatura portuguesa da base nacional comum curricular
}

No que diz respeito à Área de Linguagens, a proposta da Base Nacional Comum Curricular manifesta, de maneira enfática, persistente, a preocupação com o desenvolvimento de um conhecimento que não se construa a partir de compartimentos estanques, de modo a promover-se no ambiente escolar a percepção do caráter multifacetado, interativo do mundo em que o aluno vive e para o qual a escola o prepara. Tal preocupação sintetiza-se em passagens do texto da proposta em que se leem afirmações como “a vida em sociedade requer que os sujeitos se apropriem dos sistemas de representação e de repertórios historicamente construídos.”

Muito acertadamente observa-se neste trecho que a inserção social do sujeito exija que ele domine - aproprie-se, diz o texto - todo um conjunto de representações - no qual, inegavelmente, a produção literária tem papel de destaque - cujo lastro é histórico. Como se trata da preparação do aluno para, à partida, uma experiência direta com a sociedade brasileira, o leitor da proposta imagina que um número expressivo das forças históricas em jogo na constituição dessa sociedade será contemplado pelo currículo, evidenciando-se as interlocuções e embates que formaram e formam o que se chama de Brasil, o que implicaria em levar para a sala de aula as experiências culturais dos índios, dos portugueses, dos negros e dos imigrantes neste amplo território, à medida que aqui chegaram e se foram relacionando. A consciência manifesta do lastro histórico, pensa o leitor, estaria em sintonia com o outro grande interesse da proposta: “compreender a diversidade de manifestações linguísticas, artísticas e de práticas corporais como construções sociais e culturais, relacionando-as com ideologias e relações de poder”, item 4 dos objetivos gerais da área de linguagens da educação básica, cujo conteúdo orienta o texto como um todo, uma vez que nos estágios subsequentes do processo formativo reforça-se "o contato com produções literárias, representativas da diversidade cultural e linguística” como objetivo.

Entretanto, à medida que a leitura da proposta avança, cria-se um descompasso entre a percepção sugerida pela afirmação destacada acima e aquilo que efetivamente se propõe como prática escolar, pois a consciência a respeito do caráter histórico das representações, das quais o sujeito deverá apropriar-se para, como tal, viver em sociedade, vai dando lugar a um interesse voltado marcadamente para o contexto contemporâneo e suas questões, o que fica evidente nesta passagem: “o trabalho com cada um dos componentes curriculares que compõem a área deve, portanto, possibilitar a compreensão do mundo em que vivemos com vistas a acolher a pluralidade e a dinamicidade das práticas linguísticas, artísticas e culturais. 
Determinadas problemáticas do mundo contemporâneo e alguns temas são particularmente relevantes, para construir a relação dos conhecimentos, na área de Linguagens, com a participação cidadã, tais como: identidades e interculturalidades, modos e processos de subjetivação, tecnologias de informação e comunicação, ciências, culturas e patrimônio, relações étnico-raciais, ambiente e sustentabilidade, lazer e trabalho.”

Assim é que toda a atenção do currículo volta-se para certos elementos contemporaneamente valorizados como essenciais para aquela "participação cidadã”, esquecendo-se de que tal valorização é, também ela, um “repertório historicamente construído”. Aquilo que se destaca como questões essenciais na contemporaneidade - como "ambiente”, "sustentabilidade”, "tecnologia” - que se acredita ser absolutamente imprescindível discutir com as crianças e jovens em formação, talvez pouco ou nada signifique em um futuro próximo. É preciso, então, antes de mais nada, ajudá-los a compreender como chegamos a tais valores, quais as bases do tal "repertório historicamente construído". Não se trata, portanto, de minimizar a importância de tais questões, mas de inscrevê-las num movimento projetivo-retrospectivo, em que o olhar não se restrinja à contemplação do que se apresenta imediatamente à vista, mas abarque o que, apesar da distância temporal, mantém-se como parte fundante da experiência vivida no presente. É o que nos ensina, desde 1972, Paulinho da Viola em Dança da Solidão, exemplar perfeito da tradição popular brasileira: "meu pai sempre me dizia, meu filho, tome cuidado,/ quando eu penso no futuro, não esqueço o meu passado.”

Na ânsia de atender às urgências dos discursos contemporâneos, assume-se que o currículo contemplará não a grande base das culturas e literaturas envolvidas na consolidação da multifacetada identidade brasileira, mas apenas a parcela que, de acordo com o discurso em voga, pautado na oposição colonizadores/colonizados, merece, por uma questão de compensação histórica, ser deslocado para o centro da cena. Isso explica que desde o $1^{\circ}$ ano do ensino fundamental o foco seja "ler e apreciar textos literários tradicionais, da cultura popular, afro-brasileira, africana, indígena e de outros povos”, sem qualquer referência à literatura portuguesa, ainda que se fale em “textos literários tradicionais, da cultura popular”. Diante de uma descrição como essa, torna-se difícil compreender o que se está chamando de tradicional, a que corresponde a cultura popular nesse contexto - levando-se em conta o grau de penetração da cultura portuguesa como um todo na história da sociedade e, especificamente, da cultura popular brasileira -, dificuldade que apenas se intensifica quando se pensa na insistência com que se afirma, na proposta, o comprometimento com a "diversidade cultural e linguística”.

Quando se fala a sério em “identidades” e “interculturalidades”, em “culturas” (atente-se para o termo no plural) não se pode, a sério, ignorar os processos históricos que as moldam, a partir das quais elas se constroem, ininterruptamente, a despeito do modo como se qualifique a participação 
deste ou daquele agente. Apagar a participação da cultura e da literatura portuguesas no processo de formação do Brasil não é a melhor forma de valorizar as culturas dos povos submetidos pelo colonizador é, sim, uma mutilação do passado, sua terrível sonegação às gerações contemporâneas, como argutamente observou Sérgio Buarque em Raízes do Brasil. Nesse sentido, limitar o foco no presente, ou naquilo que se reconhece como os valores positivos engendrados pelo presente, responsável pelo estabelecimento do vínculo entre os “conhecimentos” e a “participação cidadã”, é na verdade uma maneira de embotar o aluno, impedindo-o de ver o mundo numa perspectiva efetivamente complexa. Voluntariamente ignorar a incontornável importância de Portugal, de sua cultura, para o que é o Brasil - porque aquele país foi o colonizador desprezível, que a todo custo deve ser expurgado de nosso convívio? - revela um parcialismo suspeito e questionável da proposta, justamente em seus pontos mais caros, aqueles relacionados ao reconhecimento da "literatura como lugar de encontro de multiculturalidades”.

Sobretudo é preciso saber separar a opressão sofrida no nível político da bela e profunda experiência - em termos não apenas da formação das subjetividades, mas da consolidação das autoimagens coletivas - partilhada no nível do imaginário, tanto literário quanto cultural. Por que vetar aos alunos a leitura de Camões, que tão bem explorou a turbulência e os impasses do mundo quando a globalização apenas começava, primoroso em oferecer-nos “uma perspectiva de leitura comparativa entre o local e o global” (objetivo da LILP1MOA002, matéria do $1^{\circ}$ ano do ensino médio)? De Fernando Pessoa, mestre ímpar na representação da individualidade contemporânea, a um só tempo cindida e plural, base para qualquer valorização da diversidade identitária? E o que dizer de António Vieira e suas tortuosas, torturantes e torturadas excursões pelos embates entre os interesses da metrópole e da colônia? E, para que não se pense que a importância da manutenção da literatura portuguesa justifica-se apenas pelo estudo dos seus expoentes sabidamente canônicos, mencione-se a produção literária contemporânea que, em prosa e verso, vem resistindo a ditaduras, denunciando opressões, defendendo o direito à palavra de todos os que são silenciados pelo poder dominante.

Enfim, há na proposta uma muito problemática "distância entre intenção e gesto” - para evocar a precisa formulação que se encontra no Fado tropical, fruto da parceria entre o moçambicano Rui Guerra e o brasileiro Chico Buarque, num exercício em torno à intrincada rede que caracteriza as relações entre Portugal e Brasil - distância que suscita muitas perguntas, indicativas de que o caminho para se cumprir a intenção exige a mudança de gesto:

Se se fala em atentar para as "relações étnico-raciais”, como ignorar a presença portuguesa no país? 
Qual a melhor maneira de explicar aos alunos o porquê de falarmos português, se não através da literatura e cultura portuguesas?

Se se quer despertar nos alunos a "consciência da variação e das mudanças da língua e a valorização de todas as variedades como possuidoras de uma gramática eficaz e legítima” como não fazer uso das várias formas do português antes da transposição da língua para a América do Sul?

Como "ler produções literárias de autores da literatura brasileira dos séculos XVIII, XVII e XVI (...) percebendo a literatura como produção historicamente situada e, ainda assim, atemporal e universal" - objetivo da LILP3MOA001, matéria do $3^{\circ}$ ano do ensino médio -, sem apresentar o aluno ao referencial literário português?

Pelo que acima foi exposto, a ABRAPLIP, Associação Brasileira de Professores de Literatura Portuguesa, composta de professores e pesquisadores cujo trabalho desenvolve-se sem perder de vista os muitos diálogos entre a literatura portuguesa e as demais literaturas produzidas em português, considera lamentavelmente equivocada a opção do Ministério da Educação e Cultura por retirar a literatura portuguesa da Base Nacional Comum Curricular e pede uma revisão dessa proposta em relação à compreensão maior de que estudar a cultura brasileira, suas linguagens e seus gestos, é abrir-se necessariamente ao estudo das literaturas de língua portuguesa, entre as quais está a literatura portuguesa, que tanto importa para que o aluno brasileiro perceba em real perspectiva sua cultura, seu passado e seu presente. Sem esse diálogo intercultural, que futuro linguístico e literário a educação brasileira poderá efetivamente construir?

DIRETORIA DAABRAPLIP - Associação Brasileira de Professores de Literatura Portuguesa

Presidente: Patrícia da Silva Cardoso

Vice-presidente: Jorge Valentim

Secretário executivo: Antonio Augusto Nery

Secretário adjunto: Rosana Apolonia Harmuch

Tesoureiro executivo: Luís Bueno

Tesoureiro adjunto: Marcelo Sandmann

Assessor de comunicação: Luciene Pavanello

Conselho Deliberativo e Fiscal

Regional 1 (RJ e ES): Ida Alves e Mônica Figueiredo

Regional 2 (SP e MS): Paulo Motta e Renata Junqueira

Regional 3 (BA, SE, AL): Márcio Muniz e Flávio Reis

Regional 4 (PE, PB, RN, CE, MA, PI): Márcia Manir e Ana Márcia Siqueira 
Regional 5 (RS, SC E PR): Simone Schimidt e Tatiana Prevedello Regional 6 (MG, GO, TO, DF): Raquel Madanelo e Daviane Moreira Regional 7 (AM, AP, AC, PA, RO, RR, MT): Otávio Rios e Sílvio Holanda. 